\title{
Bond strength and marginal adaptation of a novel root-end filling material
}

\author{
Yousra Aly ${ }^{*}$, Sherif El Shershaby and Sammar El-Sherif
}

\begin{abstract}
Background: Apicoectomy with retrograde filling is considered as a tooth saver. Mineral trioxide aggregate (MTA) is mostly recommended as a root-end filling material as it is proved to have excellent sealing ability and hard tissue repair. Aside from these advantages, MTA has some disadvantages, such as weak handling properties, long setting time, and discoloration potential. Nanotechnology is now undergoing rapid development. Recently, experimental nano-white mineral trioxide aggregate (nano-WMTA) was prepared and introduced by NanoTech Egypt (Al Giza, Egypt) as a root-end filling material. The manufacturers claim that it has similar composition to white MTA, but with the reduction of its particle size to obtain a high specific powder surface area that may lead to a better and faster hydration process. It seems worthy to study the bond strength and marginal adaptation of the newly introduced nano root-end filling materials and compare it with the conventionally used MTA in root-end cavities.

Results: In push-out test, no statistically significant difference was found between nano-WMTA and MTA Angelus groups where $p=0.459$. The nano-WMTA group recorded the highest mean value. For scanning electron microscope evaluation, there was a statistically significant difference between the nano-WMTA and MTA Angelus groups where $p<0.001$. The MTA Angelus group recorded the highest mean value of gap distance.

Conclusions: Nano-WMTA recorded a similar bond strength to MTA Angelus. The nano-WMTA showed significantly higher marginal adaptation to root-end cavity than MTA Angelus.
\end{abstract}

Keywords: Bond strength, Nano-WMTA, Root-end cavity, Marginal adaptation

\section{Background}

Apicoectomy with retrograde filling is a well-known alternative in endodontics in case of orthograde endodontic therapy failure (Gutmann and Harrison 1999). It is then considered as a tooth saver. Many materials such as amalgam, zinc-oxide eugenol cements, MTA, glass ionomer cements, composite resins, Biodentine, EndoSequence, and Bioaggregate have been used as retrograde filling materials. When compared to other retrograde filling materials, MTA proved to have excellent sealing ability and hard tissue repair. The major constituents of MTA are tricalcium silicate, tricalcium aluminate, tricalcium oxide, and silicate oxide. MTA is mostly recommended as a root-end filling material due to its

\footnotetext{
* Correspondence: yousraaly2010@gmail.com

Restorative and Dental Materials Department, National Research Centre, Cairo, Egypt
}

\section{Springer Open}

(c) The Author(s). 2020 Open Access This article is licensed under a Creative Commons Attribution 4.0 International License, which permits use, sharing, adaptation, distribution and reproduction in any medium or format, as long as you give appropriate credit to the original author(s) and the source, provide a link to the Creative Commons licence, and indicate if changes were made. The images or other third party material in this article are included in the article's Creative Commons licence, unless indicated otherwise in a credit line to the material. If material is not included in the article's Creative Commons licence and your intended use is not permitted by statutory regulation or exceeds the permitted use, you will need to obtain permission directly from the copyright holder. To view a copy of this licence, visit http://creativecommons.org/licenses/by/4.0/.

biocompatibility as well as its osteogenic and regenerative potential (Saunders 2008). Aside from these advantages, MTA has some disadvantages, such as weak handling properties, long setting time, and discoloration potential (Parirokh and Torabinejad 2010; Estrela et al. 2000; Asgary et al. 2008).

Nanotechnology is now undergoing rapid development. Nanomaterials are characterized by the reduced size of their external dimensions which is in the range of 1-100 nm. This size modification showed a significant positive effect on their property (Xie et al. 2013; Wang et al. 2007). The addition of nanoparticles and nanotubes showed improvement of the cement hydrate properties (Saghiri et al. 2012; Saghiri et al. 2013a).

Recently, experimental nano-white mineral trioxide aggregate (nano-WMTA) was prepared by NanoTech Egypt (Al Giza, Egypt). Nano-WMTA is a newly 
introduced root-end filling cement. The manufacturers claim that it has similar composition to WMTA, but with the reduction of its particle size to obtain a high specific powder surface area that may lead to a better and faster hydration process.

Marginal adaptation is a key factor in endodontic surgery success (Stabholz et al. 1985; Peters and Peters 2002a).

Moreover, long-term clinical success is depending on the good bond strength of endodontic materials to root dentin (Nikhade et al. 2016). Good adhesion of the material to dentin leads to resistance of dislodgment forces occurring during function (Shahi et al. 2012). The pushout test has been considered as a more valid way than the tensile shear bond strength for the evaluation of the adhesiveness of a material to its surrounding dentin (Saghiri et al. 2013b; Shokouhinejad et al. 2010).

It seems worthy to study the bond strength and marginal adaptation of the newly introduced nano root-end filling materials and compare it with the conventionally used MTA in root-end cavities.

\section{Methods}

\section{Preparation of nano-WMTA}

Nano-WMTA was prepared in NanoTech Egypt labs (Al Giza, Egypt) (Table 1). White MTA was synthesized by the sol-gel method following Voicu et al. (Voicu et al. 2012): both calcium nitrate and aluminum nitrate were dissolved in $180 \mathrm{ml}$ water until a clear solution was gained, using a magnetic stirrer. TEOS was hydrolyzed using a molar ratio TEOS (tetraethyl orthosilicate) to water of 1:4. The two solutions were integrated and constantly stirred at $60^{\circ} \mathrm{C}$ for $4 \mathrm{~h}$, then held at $70{ }^{\circ} \mathrm{C}$ for 96 $\mathrm{h}$, to enable the water evaporation and to speed up the poly-condensation reaction, leading to the formation of a viscous gel. Drying this gel was then done for $420 \mathrm{~h}$ at $120^{\circ} \mathrm{C}$, obtaining a white powder as the final product. The powders were compressed in pellets and thermally cured for $30 \mathrm{~min}$, at $1350^{\circ} \mathrm{C}$. This was followed by rapid cooling in air and grinding in a laboratory planetary mill for $2 \mathrm{~h}$ (Voicu et al. 2012).

\section{Experimental WMTA characterization}

Transmission electron microscope (TEM) images were taken using the JEOL JEM-2100 (Japan) microscope operated at accelerating voltage of $200 \mathrm{kV}$ with a resolution of $1.402 \AA$.

\section{Specimen preparation}

Specimen selection

Forty single-rooted freshly extracted human teeth with mature apices, without any root caries, root fracture, or resorption, were selected. Teeth were carefully cleaned with curettes to remove any soft tissue remnants, placed in $2.5 \%$ sodium hypochlorite $\mathrm{NaOCl}$ for $1 \mathrm{~h}$ to allow for surface disinfection, and then stored in saline solution until instrumentation.

\section{Specimen preparation}

The teeth were decoronated to create root sample with a standardized length of $16 \mathrm{~mm}$ using a safe-sided diamond disk mounted in a low-speed handpiece under water coolant. The working length was measured by subtracting $1 \mathrm{~mm}$ from the length recorded when the tip of a \# $15 \mathrm{~K}$-file was visible at the apical foramina. The root canals were prepared using Protaper rotary system to an apical preparation size F5.

Irrigation of the canals with $1 \mathrm{ml}$ of $2.5 \% \mathrm{NaOCl}$ was done between each instrument. After completion of the instrumentation, the smear layer was removed with $3 \mathrm{ml}$ of $17 \%$ EDTA for $3 \mathrm{~min}$ followed by $3 \mathrm{ml} 5.25 \% \mathrm{NaOCl}$. Finally, each canal was flushed with $3 \mathrm{ml}$ distilled water then dried with paper points. Then, the root canals were dried with paper points and obturated with gutta-percha F5 and AH Plus root canal sealer. The teeth were then stored at $37^{\circ} \mathrm{C}$ and $100 \%$ humidity for 1 week.

\section{Root-end preparation}

The root-ends were then resected perpendicular to the long axes of the teeth using a high-speed handpiece and air water spray with a tapered fissure bur $3 \mathrm{~mm}$ from the anatomic apex. Three-millimeter-deep root-end cavities were prepared with retro tip attached to an ultrasonic unit.

\section{Root-end filling}

The materials were mixed according to the instructions proposed by the manufacturer and to a consistency that promoted the material to preserve its shape and attachment to the plastic instrument and plugged with a microplugger. After filling the root-end cavity, a cotton wall pledget dampened with sterile saline was used to clean the surface of the cut root-end.

Specimens were divided into 2 groups $(n=20)$ according to tested material.

Table 1 Materials used in this study

\begin{tabular}{lll}
\hline Materials & Manufacturers & Composition \\
\hline MTA Angelus & Angelus, Londrina, PR, Brazil & $\begin{array}{l}\text { Tri-calcium silicate, di-calcium silicate, tri-calcium aluminate, ferroaluminate tri-calcium, } \\
\text { calcium oxide, bismuth oxide }\end{array}$ \\
Experimental nano-WMTA & NanoTech Egypt, Al Giza, Egypt $\begin{array}{l}\text { Reduced white MTA particles and adding tri-calcium aluminate, calcium sulfate, zeolite } \\
\text { and strontium }\end{array}$ \\
\hline
\end{tabular}


Group I: Root-end cavities were filled with MTA Angelus (Angelus, Londrina, PR, Brazil)

Group II: Root-end cavities were filled with experimental nano-WMTA, NanoTech Egypt. The specimens were then stored in $100 \%$ humidity at $37^{\circ} \mathrm{C}$ for 1 week before testing.

\section{Methods of evaluation Push-out test}

Ten specimens of each group were used in this part of the study. Each specimen was transversely sectioned perpendicular to the long axis of the root using a watercooled precision saw to obtain a section $2 \mathrm{~mm} \pm 0.1$ in thickness from the apical thirds using a digital caliper (Pachymeter, Electronic Digital Instruments, China). Each section was coded and photographed from apical and coronal surfaces using a stereomicroscope (SZ-PT; Olympus, Tokyo, Japan) at an original magnification of $\times 65$. Calibration was performed by comparing an object of known length, a ruler in this study, using the "Set Scale" tool generated by the image analysis software (Image J; NIH, Bethesda, MD). The diameter of the filling was then measured, and the radius was calculated.

Each root slice was mounted in custom-made loading fixture (metallic block with circular cavity at the middle, this cavity for specimen housing having a central whole to facilitate displacement of extruded filling material), and then subjected to compressive loading at a crosshead speed of $1 \mathrm{~mm} / \mathrm{min}$ via a computer-controlled material testing machine (Model 3345; Instron Industrial Products, Norwood, MA, USA).

Load was applied by plunger of $1 \mathrm{~mm}$ diameter corresponding to the radicular third to be tested. The plunger tip was sized and positioned to touch only the filling, without stressing the surrounding dentin, in apical coronal direction to push the filling toward the larger diameter, thus avoiding any limitation to the filling movement possibly owing to the canal taper. This way, it was guaranteed that the overlaying dentin was sufficiently supported during the loading process.

The maximum failure load was recorded in Newton and converted into MPa.

The bond strength was calculated from the recorded peak load divided by the computed surface area as calculated by the following formula (Nagas et al. 2007):

$$
\left[\mathrm{A}=\left(3.14 * \mathrm{H} *\left(\mathrm{r}^{1}+\mathrm{r}^{2}\right)\right]\right.
$$

where $r^{1}$ is the apical radius, $r^{2}$ is the coronal one, and $h$ is the thickness of the sample in millimeters.

Failure manifested by extrusion of filling piece and confirmed by a sudden drop along the load-deflection curve was recorded by the Bluehill computer software.
The push-out bond strength was determined for each root slice.

\section{Scanning electron microscope (SEM) evaluation}

The specimen sections were placed in a vial containing $2.25 \%$ sodium hypochlorite solution for $3 \mathrm{~h}$. The specimens were dehydrated for $5 \mathrm{~h}$ in increasing concentrations of alcohol 70, 90, and 99\%. The samples were then air-dried, sputter-coated with gold using a fine-coat ion sputter JFC-1100 (fine coat ion sputter JFC-1100, JEOL Ltd., Tokyo, Japan), and then evaluated using scanning electron microscope (SEM) (Jeol JSM-6360 LV, JEOL Ltd.). Postoperative scanning electron photomicrographs were made of each specimen to compare the gap distance at the interface between the retrofilling material and the prepared root surface.

\section{Statistical analysis}

The mean and standard deviation values were calculated for each group in each test. Data were explored for normality using Kolmogorov-Smirnov and Shapiro-Wilk tests and showed parametric (normal) distribution. Independent sample $t$ test was used to compare between two groups in non-related samples.

The significance level was set at $p \leq 0.05$. Statistical analysis was performed with $\mathrm{IBM}^{\odot} \mathrm{SPSS}^{\circ}$ Statistics Version 20 for Windows.

\section{Results}

Push-out test (Table 2 and Fig. 1)

No statistically significant difference was found between the nano-WMTA and MTA Angelus groups where $p=$ 0.459 . The nano-WMTA group recorded the highest mean value, while the MTA Angelus group recorded the least mean value.

\section{SEM (gap distance) (Table 2 and Fig. 2)}

There was a statistically significant difference between the nano-WMTA and MTA Angelus groups where $p<$ 0.001. The MTA Angelus group recorded the highest

Table 2 The mean and standard deviation (SD) values of pushout and SEM of different groups

\begin{tabular}{|c|c|c|c|c|}
\hline \multirow[t]{3}{*}{ Variables } & \multicolumn{4}{|c|}{ Evaluation methods } \\
\hline & \multicolumn{2}{|c|}{ Push-out } & \multicolumn{2}{|c|}{ SEM (gap distance) } \\
\hline & Mean & SD & Mean & SD \\
\hline Nano-WMTA & $1.65^{a}$ & 0.30 & $6.53^{b}$ & 1.28 \\
\hline MTA (Angelus) & $1.52^{\mathrm{a}}$ & 0.24 & $14.22^{a}$ & 2.29 \\
\hline$p$ value & \multicolumn{2}{|c|}{0.459 ns } & \multicolumn{2}{|c|}{$<0.001^{*}$} \\
\hline
\end{tabular}

Means with different letters in the same column indicate statistically significance difference

ns non-significant $(p>0.05)$

*Significant $(p<0.05)$ 


\section{Push-Out}

\section{5}

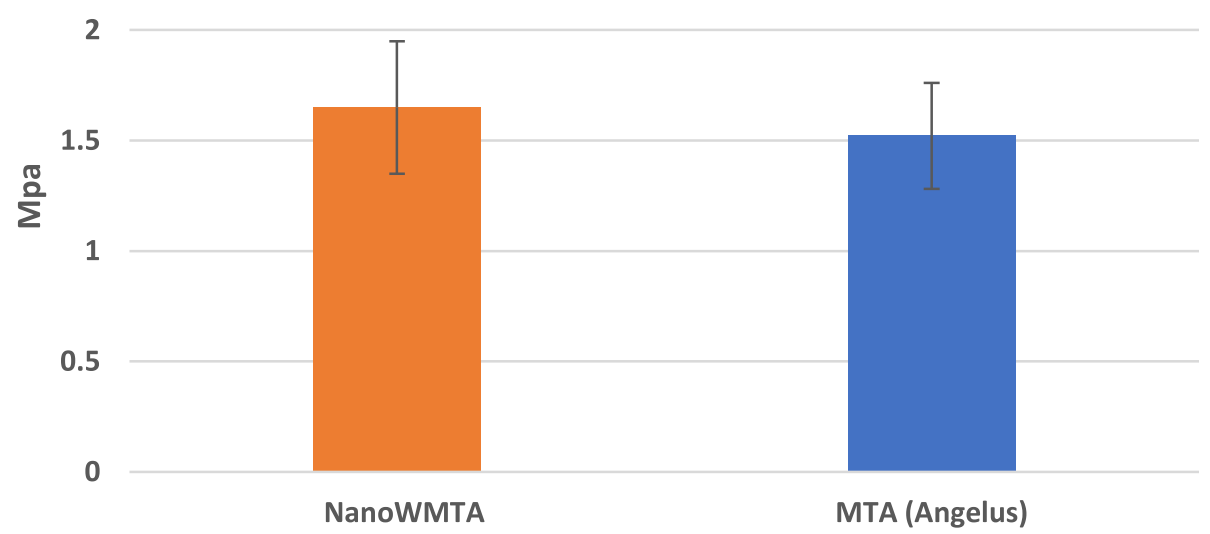

Fig. 1 Histogram showing push-out results for NMTA and MTA Angelus

mean value, while the nano-WMTA group recorded the least mean value.

\section{Discussion}

In this study, the push-out bond strength and marginal adaptation of a new experimental nano-WMTA was compared to MTA Angelus. Three-millimeter-deep root-end cavities were prepared with retro tip attached to an ultrasonic unit. Studies conducted by Rainwater et al. (Rainwater et al. 2000) and De lange et al. (De lange et al. 2007) proved a higher sealing ability of retrograde filling when retrograde cavity was prepared by ultrasonic tip rather than bur. The smooth cavity margins obtained with ultrasonic tips positively affected the delivery of materials into the cavities and enhanced their seal (Plotino et al. 2007). Nowadays, the MTA is the mostly used as retrograde filling material. The MTA composition and its release of $\mathrm{Ca}^{2+}$ and $\mathrm{OH}$ ions during hydration explain its special biological properties (Saghiri et al. 2015). After root-end filling by either MTA Angelus or nano-WMTA, the specimens were then kept in $100 \%$ humidity at $37^{\circ} \mathrm{C}$ for 1 week before testing. A significant increase in the bond strength values between root dentin and MTA was obtained when allowed to set after 7 days compared to those tested after 1 day of storage (Aggarwal et al. 2013). Moreover, the Nikhade et al. (Nikhade et al. 2016) study

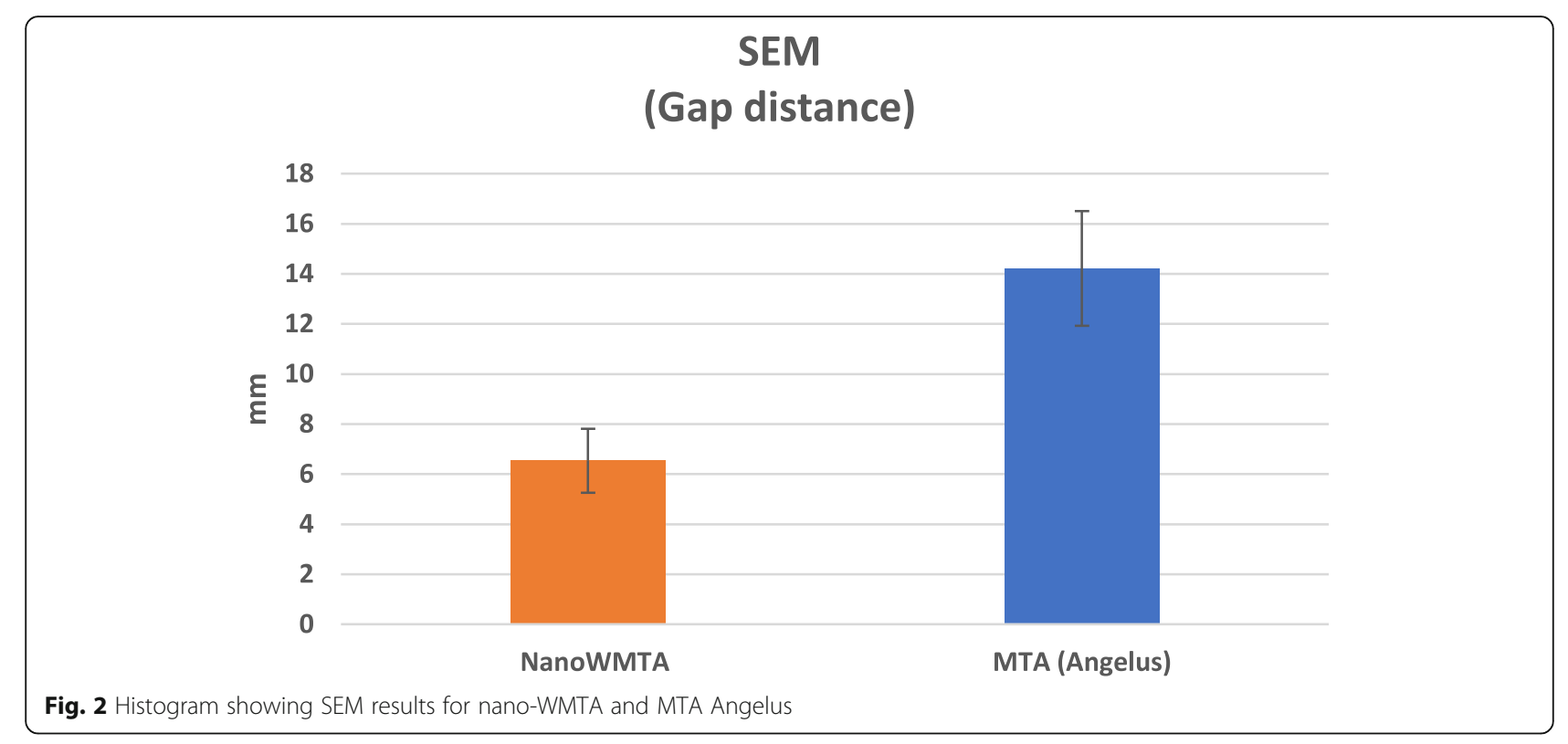




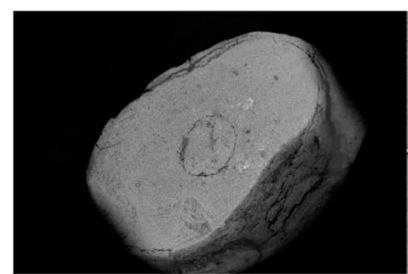

A

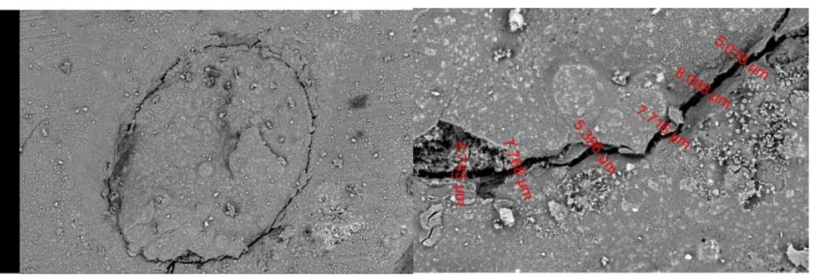

$\mathrm{B}$
$\mathrm{C}$

Fig. 3 SEM images of nano-WMTA. a $\times 50 . \mathbf{b} \times 250 . \mathbf{c} \times 1000$

showed an increase in bond strength for calcium silicatebased materials when incubation times were increased.

The push-out test simulating clinical stresses is considered a valuable way to evaluate the bond between the material and root dentin (Hong et al. 2010). It shows the true shear bond strength of a material as in push-out test procedures, fracture occurs parallel to the cementdentin interface (Nikhade et al. 2016).

Root canal treatment success depends on the apical sealing whether in conventional or surgical treatment. Marginal adaptation of biocompatible root-end filling materials is essential to prevent microleakage (Lee et al. 1993; Radeva et al. 2014; Morgan and Marshall 1999).

The marginal adaptation of filling materials is evaluated by scanning electron microscopy (SEM) (Morgan and Marshall 1999; Peters and Peters 2002b). The high magnifications of SEM help in the measurement of the gap interface between the dentin and retrograde filling material and thus analyzing the marginal adaptation (Oliveira et al. 2013; Malhotra and Hegde 2015).

In this study, the nano-WMTA specimens showed a higher push-out bond strength than MTA Angelus but with no significant difference between them. It has been reported that MTA cannot bond chemically to root dentin. The calcium and hydroxyl ions released from MTA interacts with the phosphate in body fluid forming interfacial deposits (Bozeman et al. 2006). These deposits lead to obliteration of the gaps between the MTA and root dentin thus increasing the MTA frictional resistance (Tay and Pashley 2007). During MTA mixing, powder reacts with water and calcium silicate hydrate and calcium hydroxide phases producing calcium ions (Camilleri et al. 2013). Calcium carbonate and calcium hydroxide deposits are then obtained as a result of calcium ion reaction with carbon dioxide and water (Camilleri 2007). The poor solubility of calcium carbonate in water leads to precipitate formation improving the MTA sealing ability and thus its frictional resistance (Han et al. 2015). Upon setting, MTA acts as a primary monoblock (Tay and Pashley 2007; Iqbal and Qureshi 2014). This might have increased its push-out bond strength (Tay and Pashley 2007).

Our results are in disagreement with Saghiri et al. (Saghiri et al. 2013b) results who found a significantly higher push-out bond strength of nanoWMTA over MTA angelus. The cause of this may be attributed to the different methodology that used dentin disks from the middle thirds of the root and may be due to the different manufacturers of nanoWMTA.

In SEM results, nano-WMTA showed better adaptation than the MTA Angelus. The MTA Angelus showed a significantly higher gap than nano-WMTA (Figs. 3 and 4). The differences of ingredients between these two cements as listed in Table 1 may explain these findings. In nano-WMTA, the decreased size of its constituents and the increase of its powder surface area as well as the uniform distribution of strontium can create better interlocking bonds with dentin (Saghiri et al. 2012). These findings may clarify the difference in adaptation detected between nanoWMTA and MTA Angelus group samples.

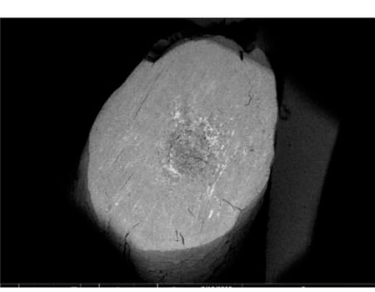

A

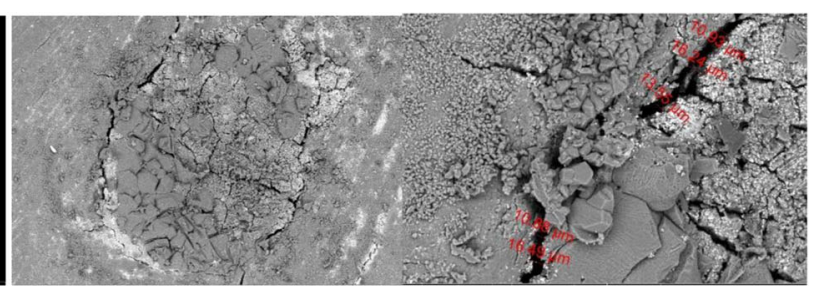

B
C

Fig. 4 SEM images of MTA Angelus. $\mathbf{a} \times 50 . \mathbf{b} \times 250 . \mathbf{c} \times 1000$ 


\section{Conclusions}

Based on the results of this in vitro study, the nanoWMTA and MTA Angelus were not significantly different in push-out bond strength. SEM images showed the presence of gaps in the root-end filling materials in both groups. Nano-WMTA has better performance in marginal adaptation than MTA Angelus.

\section{Recommendations}

Although the results of this study are really promising, further studies on other properties of this new nanomaterial should be carried on before its routine clinical use.

\section{Abbreviations}

MTA: Mineral trioxide aggregate; NWMTA: Nano-white mineral trioxide aggregate; SEM: Scanning electron microscope; $\mathrm{NaOCl}$ : Sodium hypochlorite

\section{Acknowledgements}

Not applicable.

\section{Authors' contributions}

Dr. YA and Dr. S El Shershaby performed the biomechanical preparation and obturation of the specimen. They performed also the root-end cavity preparation and filling for all specimen. Dr. S El-Sherif analyzed the data regarding the pushout test and scanning electron microscope evaluation. Dr. YA and Dr. S El-Sherif were the major contributors in writing the manuscript. All authors read and approved the final manuscript.

\section{Funding}

This work was self-funded by the authors.

\section{Availability of data and materials}

All data generated or analyzed during this study are included in this study.

\section{Ethics approval and consent to participate}

National Research Centre Ethics committee approval 20/050

\section{Consent for publication}

Not applicable

\section{Competing interests}

The authors declare that they have no competing interests.

Received: 13 June 2020 Accepted: 14 August 2020

Published online: 27 August 2020

\section{References}

Aggarwal V, Singla M, Miglani S, Kohli S (2013) Comparative evaluation of pushout bond strength of proRoot MTA, biodentine, and MTA plus in furcation perforation repair. J Conserv Dent 16:462-465

Asgary S, Eghbal MJ, Parirokh M (2008) Sealing ability of a novel endodontic cement as a root-end filling material. J Biomed Mater Res A. $87: 706-709$

Bozeman TB, Lemon RR, Eleazer PD (2006) Elemental analysis of crystal precipitate from gray and white MTA. J Endod 32:425-428

Camilleri J (2007) Hydration mechanisms of mineral trioxide aggregate. Int Endod J 40:462-470

Camilleri J, Formosa L, Damidot D (2013) The setting characteristics of MTA plus in different environmental conditions. Int Endod J 46:831-840

De lange J, Patters T, Baas EM, Ingen JM (2007) Ultrasonic root-end preparation in apical surgery: a prospective and randomized study. Oral Surg Oral Med Oral Pathol Oral RadiolEEndod 104:841-854

Estrela C, Bammann LL, Estrela C, Silva RS, Pécora JD (2000) Antimicrobial and chemical study of MTA, Portland cement, calcium hydroxide paste, Sealapex and Dycal. Braz Dent J. 11:3-9
Gutmann and Harrison, Gutmann's surgical endodontics, 1999

Han L, Kodama S, Okiji T (2015) Evaluation of calcium-releasing and apatiteforming abilities of fast-setting calcium silicate-based endodontic materials. Int Endod J 48:124-130

Hong ST, Bae KS, Baek SH, Kum KY, Shon WJ, Lee W et al (2010) Effects of root canal irrigants on the push-out strength and hydration behavior of accelerated mineral trioxide aggregate in its early setting phase. J Endod 36: 1995-1999

lqbal Z, Qureshi AH (2014) MTA monoblock obturation technique in endodontic retreatment. J Coll Physicians Surg Pak 24(Suppl 3):S180-S182

Lee SJ, Monsef M, Torabinejad M (1993) Sealing ability of a mineral trioxide aggregate for repair of lateral root perforations. J Endod. 19(11):541-544

Malhotra S, Hegde MN (2015) Analysis of marginal seal of ProRoot MTA, MTA Angelus biodentine, and glass ionomer cement as root-end filling materials: an in vitro study. J Oral Res Rev 7:44-49

Morgan LA, Marshall JG (1999) A scanning electron microscopic study of in vivo ultrasonic root-end preparations. Journal of Endodontics 25: $567-570$

Nagas E, Cehreli ZC, Durmaz V, Vallittu PK, Lassila LV (2007) Regional push-out bond strength and coronal microleakage of Resilon after different lightcuring methods. J Endod. 33(12):1464-1468

Nikhade P, Kela S, Chandak M, Chandwani N (2016) Comparative evaluation of push-out bond strength of calcium silicate-based materials: an ex-vivo study. IOSR-JDMS 1:65-68

Oliveira HF, Gonçalves Alencar AH, José Figueiredo AP, Guedes OA, de Almeida DD, Estrela C (2013) Marginal adaptation evaluation of root-end filling materials using scanning electron microscopy. Iran Endod J. 8(4): 183-187

Parirokh M, Torabinejad M (2010) Mineral trioxide aggregate: a comprehensive literature review-part III: clinical applications, drawbacks, and mechanism of action. J Endod. 36:400-413

Peters Cl, Peters OA (2002a) Occlusal loading of EBA and MTA root end fillings in a computer-controlled masticator: a scanning electron microscopic study. Int Endod. J. 35:22-29

Peters $\mathrm{Cl}$, Peters OA (2002b) Occlusal loading of EBA and MTA root- fillings in a computer-controlled masticator: a scanning electron microscopic study. Int Endod J. 35(1):22-29

Plotino G, Pameijer CH, Grande NM, Soma F (2007) Ultrasonics in endodontics: a review of the literature. J Endod 33:81-95

Radeva E, Uzunov T, Kosturkov D (2014) Microleakge associated with retrograde filling after root end resection (in vitro study). Journal of IMAB - Annual Proceeding (Scientific Papers) 20:578-583

Rainwater A, Jeansonne BG, Sarker N (2000) Effect of root-end preparation on microcrack formation and leakage. J Endod 26:72-53

Saghiri MA, Asatourian A, Orangi J, Lotfi M, Soukup JW, Garcia-Godoy F et al (2015) Effect of particle size on calcium release and elevation of $\mathrm{pH}$ of endodontic cements. Dent Traumatol. 31:196-201

Saghiri MA, Asgar K, Lotfi M, Garcia-Godoy F (2012) Nanomodification of mineral trioxide aggregate for enhanced physiochemical properties. Int Endod J. 45: 979-988

Saghiri MA, Garcia-Godoy F, Asatourian A, Lotfi M, Banava S, KhezriBoukani K (2013a) Effect of pH on compressive strength of some modification of mineral trioxide aggregate. Med Oral Patol Oral Cir Bucal. 18:e714-e720

Saghiri MA, Garcia-Godoy F, Gutmann JL, Lotfi M, Asatourian A, Ahmadi H et al (2013b) Push-out bond strength of a nano-modified mineral trioxide aggregate. Dent Traumatol 29:323-327

Saunders WP (2008) A prospective clinical study of periradicular surgery using mineral trioxide aggregate as a root-end filling. J Endodontol 34(6):660-664

Shahi S, Rahimi S, Yavari HR, Samiei M, Janani M, Bahari M et al (2012) Effects of various mixing techniques on push-out bond strengths of white mineral trioxide aggregate. J Endod 38:501-504

Shokouhinejad N, Nekoofar MH, Iravani A, Kharrazifard MJ, Dummer PM (2010) Effect of acidic environment on the push-out bond strength of mineral trioxide aggregate. J Endod 36:871-874

Stabholz A, Friedman S, Abed J (1985) Marginal adaptation of retrograde fillings and its correlation with sealability. J. Endod. 11:218-223

Tay FR, Pashley DH (2007) Monoblocks in root canals: a hypothetical or a tangible goal. J Endod 33:391-398 
Voicu G, BaDaNoiu Al, Ghit Ulica CD et al (2012) Sol-gel synthesis of white mineral trioxide aggregate with potential use as biocement. Digest J Nanomater Biostruct 7:1639-1646

Wang H, Li Y, Zuo Y, Li J, Ma S, Cheng L (2007) Biocompatibility and osteogenesis of biomimetic nano-hydroxyapatite/polyamide composite scaffolds for bone tissue engineering. Biomaterials. 28:3338-3348

Xie KY, Wang Y, Zhao Y, Chang L, Wang G, Chen Z et al (2013) Nanocrystalline $\beta$ Ti alloy with high hardness, low Young's modulus and excellent in vitro biocompatibility for biomedical applications. Mater Sci Eng C. 33:3530-3536

\section{Publisher's Note}

Springer Nature remains neutral with regard to jurisdictional claims in published maps and institutional affiliations.

\section{Submit your manuscript to a SpringerOpen ${ }^{\circ}$ journal and benefit from:}

- Convenient online submission

Rigorous peer review

- Open access: articles freely available online

High visibility within the field

- Retaining the copyright to your article

Submit your next manuscript at $\boldsymbol{\nabla}$ springeropen.com 